\title{
Competência Percebida e Desempenho Escolar em Matemática
}

\author{
MARIA DE FÁTIMA SIMÕES \\ Departamento de Psicologia e Educação da Universidade da Beira \\ Interior, Portugal \\ fsimoes@ubi.pt \\ MARIA EUGÉNIA FERRÃO \\ Departamento de Matemática da Universidade da Beira Interior, Portugal \\ meferrao@noe.ubi.pt
}

\begin{abstract}
Resumo
A competência percebida é um conceito muito pesquisado no âmbito educacional. O seu interesse deriva da sua influência num vasto conjunto de variáveis das quais se destacam aquelas que motivam os indivíduos para a ação, especialmente quando destes depende a execução de tarefas com sucesso. Já existe algum consenso entre os pesquisadores sobre a idéia de que quando os alunos demonstram uma competência percebida ajustada as suas características pessoais e sociais estarão também melhor adaptadas, independentemente do nível de realização ou da capacidade individual. Com efeito, nesse caso, a competência percebida interfere na motivação, levando os indivíduos a prosseguir com os seus objetivos. No decorrer deste artigo explora-se a relação da competência pessoal percebida com o desempenho escolar em Matemática, para identificar grupos de risco. Um modelo de regressão múltipla é aplicado à subamostra de dados do Saeb, selecionados em 2001 no Rio de Janeiro, referentes à $4^{\mathrm{a}}$ e $8^{\mathrm{a}}$ séries do Ensino Fundamental e à $3^{\mathrm{a}}$ série do Ensino Médio. Controlando por sexo, defasagem idade-série, motivação para estudar Matemática, raça e nível socioeconômico, as estimativas obtidas mostram a associação entre a competência percebida e o desempenho em Matemática. Um modelo logístico permite identificar grupos de risco na avaliação da competência.

Palavras-chave: competência percebida, desempenho em Matemática, Saeb, modelos de regressão linear.
\end{abstract}

\section{Resumen}

La competencia percibida es un concepto extensamente investigado en la esfera educativa. $\mathrm{Su}$ interés se deriva de su influencia sobre un amplio conjunto de variables entre las que sobresalen aquellas que motivan a los individuos a la acción, especialmente cuando de ellos depende ejecutar las tareas con éxito. Ya hay un consenso general entre los investigadores sobre la idea de que cuando los estudiantes tienen una opinión personal adecuada de su capacidad, sus características personales y sociales estarán también mejor adaptadas, y eso, independientemente de su nivel de realización o de su capacidad individual. De hecho, la percepción de la competencia interfiere en la motivación, haciendo que los individuos prosigan con sus objetivos. A lo largo de este artículo se explora la relación que hay entre la 
competencia personal percibida y el desempeño escolar en las Matemáticas, con la finalidad de identificar grupos de riesgo. Un modelo de regresión múltiple se aplica en una submuestra de datos del Saeb recogidos en el 2001 en Río de Janeiro relativos al $4^{\circ}$ y $8^{\circ}$ grados de la Enseñanza básica y al $3^{\circ}$ año de la Enseñanza media. Así, haciendo un control por sexo, por desnivel de edad-grado, por motivación para estudiar las Matemáticas y por raza y nivel socio-económico, los resultados obtenidos demuestran un padrón de asociación entre la competencia percibida y el desempeño en las Matemáticas. Un modelo logístico ha permitido identificar los grupos de riesgo en la evaluación de la competencia.

Palabras-clave: competencia percibida, desempeño en Matemáticas, Saeb, modelos de regresión linear.

\begin{abstract}
Personal competence perception is a widely studied concept in the educational context. Its interest derives from the influence it exerts on a wide range of behavioral variables which motivate people to action, especially to actions demanding successful performance. There is general consensus amongst researchers that when students have an adjusted personal competence perception, their social and personal characteristics show a better adaptation independently of their real performance level or individual capacity. In fact, personal competence perception influences motivation making individuals continue to pursue their aims and objectives. A multiple regression model is applied on a sub-sample of Saeb data collected in 2001 in Rio de Janeiro for the $4^{\text {th }}, 8^{\text {th }}$ and $11^{\text {th }}$ grades. Controlling by gender, overage status, motivation for studying Mathematics, race and socio-economic level, the estimates show a pattern of association between personal competence perception and performance in Mathematics. A logistic model allowed us to identify risk groups among students who over-evaluate their personal competence.
\end{abstract}

Key words: competence perception, performance in Mathematics, Saeb, linear regression models. 


\section{PAPEL DA COMPETÊNCIA PESSOAL PERCEBIDA}

A melhor definição de competência pessoal percebida está ligada ao conceito de julgamentos que os indivíduos fazem acerca da sua capacidade pessoal, não sendo, no entanto, o mesmo que auto-estima. Esta última refere-se, sobretudo, à forma como os sujeitos avaliam a sua performance e gostam de si próprios, sendo mais provável que os indivíduos com uma percepção positiva das suas competências se envolvam mais facilmente em ações desafiantes, do que aqueles que percepcionam as suas competências de forma negativa. Dessa forma, os indivíduos modificam os seus comportamentos e atitudes em face das tarefas e do modo como percebem a sua competência pessoal e com a expectativa de sucesso (Bandura, 1990; Faria, 1998; Phillips, 1984, 1987; Phillips, Zimmerman, 1990; Simões, 1997).

A relação do indivíduo com a tarefa segue uma dimensão desenvolvimentista na qual a percepção pessoal de competência assume a liderança. Com efeito, essa percepção se altera com o decorrer do tempo, diferenciando-se em cada faixa etária em termos de estabilidade, tornandose cada vez mais estável e possuindo, também, alguma maleabilidade que permite aos indivíduos apostar no seu crescimento à medida que investem mais no esforço pessoal (Faria, 1998). De acordo com alguns autores, os alunos que desvalorizam a sua competência desenvolvem expectativas de auto-eficácia e fragilizam a confiança nas suas capacidades, fragilidade essa que pode ser apenas subjetiva ou, a longo prazo, tornar-se objetiva, pela influência que tem na motivação (Bandura, 1977; Dewek, 1999; Langer, Weinman, 1981; Phillips, 1987). Os indivíduos entram num processo que conduz a uma idéia ilusória de incompetência (ilusão de incompetência) que leva a uma subestimação das suas reais competências; caso haja uma sobrestimação da competência isso resultará, igualmente, em um investimento deslocado do foco de atenção do sujeito: em vez de gerir o processo de aprendizagem, centra-se no resultado (Langer, 1979; Langer, Park, 1990).

\section{FATORES DE DESENVOLVIMENTO}

Este padrão de percepções, segundo uma vasta literatura, depende de um conjunto de fatores ligados, sobretudo, aos contextos de socialização, também intervenientes no desenvolvimento do autoconceito escolar e dos quadros atribucionais. O autoconceito escolar apresenta-se como um conceito central para o comportamento e afeta as interações que o indivíduo estabelece com os outros, o desempenho escolar e o ajustamento 
individual e, por isso, está intimamente ligado ao conceito de competência pessoal percebida (Simões, 2001).

Por analogia com os fatores ou variáveis intervenientes no desenvolvimento do autoconceito, particularmente do autoconceito escolar, o desenvolvimento da competência pessoal percebida dependerá das interações que o indivíduo mantém com os outros significativos, ou seja, os pais, os professores e os pares. Nesse sentido, tanto os pais como os professores podem influenciar o desenvolvimento de um padrão negativo de percepção de competência a partir das mensagens que veicula, quer pelos comentários que podem tecer sobre as capacidades dos seus filhos, quer pelo grau de dificuldade das tarefas e da sua relação com o sucesso ou fracasso escolar, uma vez que inicialmente dependem mais de uma avaliação externa do que da auto-avaliação dos seus desempenhos objectivos (Phillips, 1984, Faria, 2002).

Numa outra perspectiva, Oerter (1989) aponta para o desenvolvimento do autoconceito escolar e de todas as dimensões a ele associadas como a competência pessoal percebida, segundo quatro níveis, o que reforça a idéia da sua dimensão desenvolvimentista e flexível, ao longo dos diferentes níveis etários. De fato, para o autor, esses níveis vão sendo adquiridos progressivamente e integrados relativamente ao sistema escolar: 1) no período pré-escolar as crianças assumem que o self está vinculado aos desempenhos; 2) durante os primeiros anos de escolaridade as crianças integram os conceitos de esforço e capacidade no desenvolvimento do autoconceito, conseguindo distingui-los um dos outros enquanto explicação para o sucesso, aumentando (ou diminuindo) a autoconfiança e a autonomia; 3) nesta fase os alunos já recorrem à comparação social com o seu grupo de referência para integrarem o conceito de capacidade; e 4) no último nível será necessário adotar uma dialética entre o indivíduo e a sociedade para que os alunos compreendam que, em última análise, a escola contribui para o desempenho de um papel ativo na sociedade.

Relativamente ao nível 2, a criança, ao interagir com pais e professores, poderá desenvolver a idéia de "ilusão de incompetência" se as interações não tiverem qualidade e eficácia suficiente de forma a moldar a autoconfiança e a autonomia da criança. De posse dessa autoconfiança e autonomia, as crianças serão capazes de adequar as suas percepções de competência ao nível de esforço necessário para gerir o processo e não centrar toda a atenção no sucesso ou fracasso. No nível 3, salientemos que há uma valorização maior do papel dos pares no desenvolvimento das percepções de competência pessoal. 
Desse modo, tal mecanismo de comparação social pode perfeitamente associar-se ao modelo do quadro de referência interno/externo proposto para explicar os resultados, aparentemente paradoxais, obtidos por um conjunto de alunos numa avaliação sobre o autoconceito escolar em Língua Materna e Matemática (Marsh, 1986). Nessa pesquisa, o autor apresenta resultados empíricos que dão conta de uma relação entre um mecanismo de comparação social e os resultados em escalas de medida do autoconceito e de suas diferentes dimensões, dando corpo a um modelo explicativo denominado modelo de quadro de referência interno/externo. Este modelo pretende explicar como se vão formando e como se relacionam os autoconceitos escolares verbal e de Matemática.

Os estudos nessa área têm concluído que o rendimento escolar em língua materna e Matemática está intimamente ligado aos autoconceitos verbal e de Matemática, respectivamente. Assim, inferir-se-ia que as medidas de autoconceito escolar nas duas áreas estivessem igualmente bastante correlacionadas, o que não se verificou, uma vez que os autoconceitos verbal e de Matemática não apresentam qualquer correlação (Marsh, 1986).

Com a proposta do modelo acima referido, o autor pretendia dar conta desses resultados aparentemente contraditórios. Com efeito, os autoconceitos escolares verbal e de Matemática formar-se-iam com base em dois processos de comparação, um externo e outro interno. O processo de comparação externa levaria os alunos a compararem as autopercepções das suas capacidades (competência percebida) verbais e de Matemática com as percepções de competência que têm relativamente aos seus colegas em cada uma das áreas. Por outro lado, com base no processo de comparação interna, os alunos comparam as suas percepções pessoais de competência verbal com as de competência em Matemática (Marsh, 1986; Marsh, Parker, 1984; Simões, 2001). No que se refere às diferenças entre os sexos Junge, Dretzke (1996) verificaram, numa amostra de alunos superdotados, que quando existem diferenças nos resultados em Matemática, estas são mediadas pela competência percebida, sendo que os rapazes superavaliam as suas capacidades.

\section{DADOS E MÉTODOS}

A componente empírica deste trabalho foi desenvolvida com base na análise dos dados do Saeb-2001 referentes à cidade do Rio de Janeiro (Brasil, 2001). A amostra dos alunos testados em Matemática é constituída por 1801 sujeitos da $4^{\text {a }}$ série, 1986 da $8^{\text {a }}$ série e 1380 da $11^{\text {a }}$ série. 
Considerando os casos válidos, na $4^{\mathrm{a}}$ série $47,8 \%$ dos alunos testados são meninas, na $8^{\text {a }}$ série são $49,8 \%$ e na $11^{\text {a }}$ série $54,0 \%$. Os dados usados neste trabalho foram recolhidos dos questionários 1 e 2 aplicados ao aluno (Brasil, 2001, p. 67 e 69) e pelo desempenho escolar de cada aluno em Matemática, adiante designada proficiência. Esta constitui a classificação estimada aplicando-se os modelos da Teoria de Resposta ao Item às respostas dos alunos nas provas coletivas aplicadas (Brasil, 2001, p. 31; 3843).

\subsection{Definição Empírica da Competência Percebida}

Como medida de competência pessoal percebida, $\mathrm{P}$, considerou-se a resposta dada pelo aluno à seguinte pergunta 1 :

"Como se considera em relação aos seus colegas de turma?"

A resposta tem os seguintes níveis:

$$
\begin{aligned}
& 1 \text { - Abaixo da média. } \\
& 2 \text { - Na média. } \\
& 3 \text { - Acima da média. }
\end{aligned}
$$

A competência percebida do aluno $i$ que freqüenta a turma $t$ é representada por $p_{i t}$.

\subsection{Definição Empírica da Competência Objetiva}

Como medida de competência objetiva, $\mathrm{O}$, considerou-se a categorização da proficiência em Matemática nas três classes acima mencionadas (abaixo da média, na média, acima da média). As categorias da variável foram estabelecidas segundo o procedimento apresentado a seguir.

Seja $m_{i t}$ a proficiência em Matemática do aluno $i$ que pertence à turma $t$. É calculada a média da proficiência em Matemática dos alunos de cada turma, bem como o respectivo erro padrão através das expressões (1) e (2), onde $n_{t}$ é o número de alunos na turma sujeitos à aplicação do teste de Matemática.

1 Incluída no questionário 2 do aluno. Esta pergunta é antecedida por outra que contribui para objetivar a resposta do aluno, que é a seguinte: “Gosta de estudar Matemática?" 


$$
\bar{M}_{t}=\frac{\sum_{i=1}^{n_{t}} m_{i t}}{n_{t}}
$$

$$
\begin{gathered}
s_{\bar{M}_{t}}=\sqrt{\frac{\sum_{i=1}^{n_{t}}\left(m_{i t}-\bar{M}_{t}\right)^{2}}{n_{t}}} \\
\mathrm{O}_{\mathrm{it}}=1 \mathrm{se}{ }^{\left.m_{i t} \in-\infty, \bar{M}_{t}-1,96 s_{M_{t}}\right\rfloor} \\
\mathrm{O}_{\mathrm{it}}=2 \mathrm{se}{ }^{m_{i t} \in\left[\bar{M}_{t}-1,96 s_{M_{t}}, \bar{M}_{t}+1,96 s_{M_{t}}\right]} \\
\mathrm{O}_{\mathrm{it}}=3 \text { se }
\end{gathered}
$$

As categorias da variável O são constituídas a partir do intervalo de confiança ${ }^{2}$ para a média da proficiência dos alunos da turma. Desse modo, o aluno cujo desempenho em Matemática pertence ao intervalo de confiança é classificado "na média" ( $\left.\mathrm{o}_{\mathrm{it}}=2\right)$, o aluno cujo desempenho em Matemática é inferior ao limite inferior do intervalo de confiança é classificado "abaixo da média" $\left(\mathrm{o}_{i t}=1\right)$, e, finalmente, o aluno cujo desempenho em Matemática é superior ao limite superior do intervalo de confiança é classificado "acima da média" $\left(\mathrm{O}_{i \mathrm{t}}=3\right)$.

\subsection{Afastamento da Competência Percebida}

$\mathrm{O}$ afastamento da competência percebida relativamente à competência objetiva, doravante designado apenas por afastamento, A, mede o quão bem o aluno percebe a sua competência em Matemática e define-se como a diferença entre a competência percebida e a competência objetiva, isto é, $a_{i t}=p_{i t}-o_{i t}$.

Quando o valor de $a_{i t}$ é zero significa que o aluno faz a avaliação adequada da sua competência, pois a competência percebida iguala a

2 Coeficiente de confiança de 0,95. 
competência objetiva. Quando o valor é positivo significa que o aluno superavalia a sua competência e, finalmente, quando o valor é negativo significa que o aluno subavalia a sua competência.

\subsection{Variáveis de Controle}

Outras variáveis individuais são usadas como controle na relação entre competência percebida e desempenho escolar em Matemática. Essas variáveis são: sexo, defasagem escolar $(\operatorname{sim} / \text { não) })^{3}$, raça/cor autodeclarada (branco, pardo/mulato, preto, indígena, amarelo), motivação (gosta da disciplina: $\operatorname{sim} /$ não).

\section{RESULTADOS}

\subsection{Análise Exploratória}

O Gráfico 1 mostra a distribuição dos alunos da $4^{\text {a }}$ e $8^{\text {a }}$ séries do Ensino Fundamental e da $3^{a}$ série do Ensino Médio pelos cinco níveis de afastamento.

\section{Gráfico 1: Distribuição do afastamento da competência percebida} segundo a série

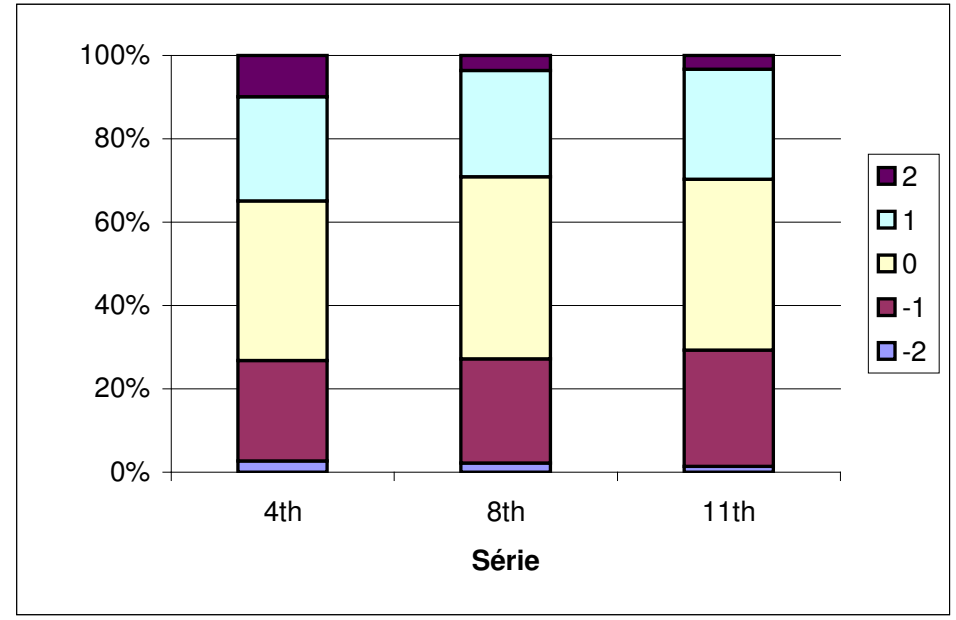

${ }^{3}$ Se o aluno freqüenta ou não a série adequada à sua idade. 
O gráfico mostra que é na $8^{\text {a }}$ série que os alunos avaliam melhor as suas competências em Matemática, pois enquanto na $8^{\text {a }}$ série $43,7 \%$ dos alunos estão nesta situação, na $11^{\text {a }}$ série tal porcentagem é de $41,0 \%$ e na $4^{\text {a }}$ série de $38 \%$.

Tanto entre as meninas como entre os meninos, a porcentagem daqueles que se superavaliam diminui da $4^{\mathrm{a}}$ para a $8^{\mathrm{a}}$ série. No entanto, $\mathrm{o}$ decréscimo é mais suave nas meninas do que nos meninos. Ao contrário, entre os meninos, é mais notável o aumento dos que se subavaliam da $4^{\mathrm{a}}$ para as séries seguintes do que entre as meninas. Com efeito, $27,3 \%$ dos meninos na $4^{a}$ série avaliam-se abaixo do seu nível, enquanto entre as meninas a porcentagem é de $27,1 \%$. Na $8^{a}$ série as porcentagens são $30,5 \%$ e $24,0 \%$ e na $11^{\text {a }}$ série $32,8 \%$ e $26,5 \%$, respectivamente.

Em todas as séries, é imperceptível a diferença porcentual dos alunos que se subavaliam, estando na idade adequada para a série, daqueles que se subavaliam, quando estão acima da idade adequada para a série que freqüentam. À exceção da $8^{\mathrm{a}}$ série, a porcentagem dos alunos que se superavaliam é mais elevada entre aqueles que se encontram com defasagem idade-série do que entre os que têm a idade adequada.

Em todas as séries estudadas, a porcentagem de alunos que avaliam corretamente a sua competência é maior entre os que declaram gostar da disciplina. Essas percentagens são: $39,0 \%, 46,7 \%$ e $43,0 \%$ na $4^{\mathrm{a}}, 8^{\mathrm{a}}$ e $11^{\mathrm{a}}$ séries, respectivamente.

A relação entre o desempenho escolar em Matemática e o afastamento da competência percebida está ilustrada no Gráfico 2, no qual é possível observar que, em qualquer série, o desempenho escolar em Matemática é inferior para níveis de afastamento da competência percebida positivos, isto é, quando os alunos superavaliam a sua competência.

\section{Gráfico 2: Relação entre o afastamento da competência percebida e o desempenho escolar}

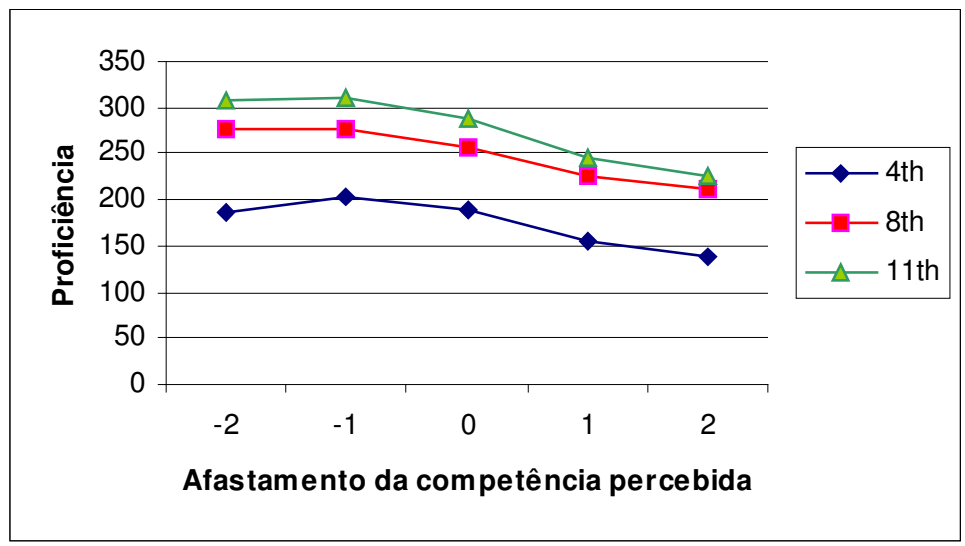




\subsection{Modelagem}

Dado que todas as variáveis tratadas anteriormente estão direta ou indiretamente relacionadas com o desempenho escolar, para quantificar a relação existente entre o afastamento da competência percebida e o desempenho, ajustou-se um modelo de regressão linear múltipla que incluísse, simultaneamente, todas elas, bem como o nível educacional da mãe ou do responsável pela educação (proxy do nível socioeconômico do aluno). Os resultados estão expostos na Tabela 1. Todas as estimativas dos parâmetros são estatisticamente significativas ao nível de significância de 0,01 .

Tabela 1: Resultados do modelo de regressão múltipla para Proficiência

\begin{tabular}{|c|c|c|c|}
\hline & & Série & \\
\hline & $4^{\mathrm{a}}$ & $8^{\mathrm{a}}$ & $11^{\mathrm{a}}$ \\
\hline Intercepto & 183,8 & 263,8 & 284,3 \\
\hline Afastamento da competência percebida $<0$ & 14,1 & 22,3 & 24,5 \\
\hline Afastamento da competência percebida $>0$ & $-34,6$ & $-31,9$ & $-39,8$ \\
\hline Sexo: Menina/Menino & $-2,6$ & $-6,1$ & $-11,4$ \\
\hline Motivação: Gosta de estudar Matemática & 16,0 & 14,2 & 18,6 \\
\hline Defasagem idade-série: Acima da idade adequada & $-20,0$ & $-26,4$ & $-26,4$ \\
\hline Raça/cor: mulato/branco & $-6,9$ & $-6,9$ & $-9,1$ \\
\hline Raça/cor: preto/branco & $-16,9$ & $-13,7$ & $-14,1$ \\
\hline Raça/cor: amarelo/branco & $-5,0$ & $-1,7$ & $-9,3$ \\
\hline Raça/cor: indígena/branco & $-6,8$ & $-10,1$ & $-30,5$ \\
\hline Nível educacional dos pais: Não sei/ $4^{\mathrm{a}}$ série & 10,6 & 2,4 & 2,5 \\
\hline Nível educacional dos pais: Nenhum $/ 4^{a}$ série & $-8,9$ & $-6,7$ & $-4,3$ \\
\hline Nível educacional dos pais: $8^{\mathrm{a}}$ série $/ 4^{\mathrm{a}}$ série & 5,8 & 2,3 & 2,3 \\
\hline Nível educacional dos pais: $11^{\mathrm{a}}$ série $/ 4^{\mathrm{a}}$ série & 12,6 & 14,6 & 20,1 \\
\hline Nível educacional dos pais: Universidade $/ 4^{\mathrm{a}}$ série & 33,5 & 45,6 & 58,3 \\
\hline$[1] \mathrm{R}^{2}$ & $38,3 \%$ & $45,6 \%$ & $51,2 \%$ \\
\hline $\begin{array}{l}\text { [2] } \mathrm{R}^{2} \text { sem as variáveis "afastamento da competência } \\
\text { percebida" }\end{array}$ & $19,2 \%$ & $29,1 \%$ & $32,7 \%$ \\
\hline$[3]=[1]-[2]$ & $19,1 \%$ & $16,5 \%$ & $18,5 \%$ \\
\hline
\end{tabular}




\subsubsection{Efeito do afastamento da competência percebida}

A partir da variável que representa o afastamento da competência percebida à competência real, e que tem cinco níveis, criaram-se duas novas variáveis mudas ${ }^{4}$ que indicam, respectivamente, se o aluno se superavalia ou se ele se subavalia.

As estimativas dos parâmetros que lhe estão associados corroboram a evidência assinalada acima, ou seja, em todas as séries estudadas, os alunos que se superavaliam têm desempenho reduzido e os que se subavaliam têm o desempenho acrescido, em relação aos alunos que adequadamente percebem a sua competência (nível de referência).

$\mathrm{Na} 4^{\mathrm{a}}$ série, o aluno que subavalia a sua competência em Matemática atinge, em média, 14,1 unidades de proficiência adicionais comparativamente ao aluno que avalia corretamente a sua competência. Comparando com o mesmo grupo, também se verifica que o aluno que se superavalia tem o desempenho reduzido, em média, em 34,6 unidades de proficiência. Observe que a distância existente entre estas estimativas é de 48,7 valores, quando a média condicionada do desempenho escolar é 183,8.

$\mathrm{Na} 8^{a}$ série ocorre algo semelhante, mas os valores são ainda mais distantes entre si (54,2 valores) pois a estimativa associada à variável de superavaliação é -31,9 e a estimativa associada à variável de subavaliação é 22,3 .

Na $11^{a}$ série a estimativa associada à superavaliação é $-39,8$ e à subavaliação é 24,5, logo a distância entre eles é de 64,3 valores.

Em geral, nota-se um esforço crescente com a idade, entre os alunos com competência percebida abaixo da objetiva, traduzido através dos valores adicionais atingidos na classificação. Por outro lado, nota-se uma inação ou falta de empenho, entre os alunos com competência percebida acima da objetiva, traduzida nos valores subtraídos à classificação.

A capacidade explicativa dos modelos é, respectivamente, 38,3\%, $45,6 \%$ e $51,2 \%$. Retiradas deste modelo as variáveis explicativas de interesse, verifica-se que a capacidade explicativa do modelo resultante é reduzida em $19,1 \%, 16,5 \%$ e $18,5 \%$ na $4^{a}, 8^{a}$ e $11^{a}$ série, respectivamente. De onde se conclui que qualquer das variáveis que representam afastamento ou a sua recodificação são fortemente correlacionadas com o desempenho escolar. Do ponto de vista do nexo de causalidade, poder-se-ia dizer que há uma certa confusão entre o que é a causa e o que é o efeito. O fato de um aluno desconhecer os fundamentos básicos da Matemática, impede-o de ter a consciência do pouco que sabe e, por isso, avalia-se acima da sua

4 Variável muda é uma variável binária que toma o valor 1 ou 0 no caso de um determinado atributo estar presente ou ausente, respectivamente. 
competência objetiva. Por sua vez, os resultados escolares serão impactados pela falta de estudo que ele necessitaria. "Mutatis mutandis", quando aluno conhece profundamente os conteúdos da Matemática, tende a avaliar-se abaixo da sua competência objetiva, levando-o a trabalhar ainda mais para satisfazer o nível de conhecimento que ele considera ser necessário. $\mathrm{Na}$ seqüência, a subavaliação causa o estudo e dedicação adicional à disciplina que será traduzido em melhores resultados.

\subsubsection{Efeito das restantes variáveis}

Os resultados do modelo sugerem que, em todas as séries, as meninas têm desempenho em Matemática inferior aos meninos. Em média, a diferença é de 2,6 valores na $4^{\text {a }}$ série, 6,1 valores na $8^{\text {a }}$ série e 11,4 valores na $11^{\mathrm{a}}$ série.

As estimativas associadas às variáveis motivação (gosta de estudar Matemática) e defasagem idade-série corroboram evidências encontradas anteriormente segundo as quais a motivação é um fator positivamente correlacionado com os resultados escolares atingidos (Barbosa, Fernandes, 2001), enquanto que a defasagem idade-série é um fator de discriminação negativa dos alunos nessa situação (Ferrão, Beltrão, Santos, 2002, 2002a).

É de se notar que o efeito do nível de escolaridade dos pais nos resultados em Matemática aumenta progressivamente da $4^{\mathrm{a}}$ até à $11^{\mathrm{a}}$ série. O nível de escolaridade dos pais é proxy do nível socioeconômico da família. A evidência do forte impacto que este tem nos resultados escolares vai ao encontro das evidências já registadas na literatura (Barbosa, Fernandes, 2000; Ferrão et al. 2001, Soares, 2003). Adicionalmente, os resultados agora encontrados sugerem a existência de seleção ao longo do sistema educacional. Verifique que o aluno da $4^{\mathrm{a}}$ série, cujo nível educacional dos pais é o universitário, atinge em média mais 33,5 valores do que os seus colegas cujo nível educacional dos pais é a $4^{a}$ série. Tal estimativa tem o valor de 45,6 e de 58,3 , respectivamente, para o aluno que freqüenta a $8^{\mathrm{a}}$ ou a $11^{\mathrm{a}}$ séries.

Relativamente às estimativas dos parâmetros associados a raça/cor, elas igualmente corroboram os resultados encontrados em Ferrão et al. (2001), segundo os quais os alunos autodeclarados de cor preta apresentam resultados escolares muito abaixo dos seus colegas. O modelo igualmente sugere que os alunos indígenas que freqüentam a $11^{\mathrm{a}}$ série atingem em média resultados 30,5 abaixo dos seus colegas brancos. 


\subsubsection{Identificação dos grupos de risco}

Tendo mostrado a correlação negativa entre desempenho escolar em Matemática e o afastamento da competência percebida, tornou-se de relevância prática a identificação dos grupos de risco, concretamente dos grupos que tendem a apresentar afastamento positivo da competência percebida, ou seja, a superavaliar as suas competências. Com esse propósito aplicou-se o modelo de regressão logística aos dados da $4^{\mathrm{a}}$ série $^{5}$. Os resultados 6 são apresentados na Tabela 2. Os valores da razão de vantagens mostram que podem ser identificados dois grupos de risco segundo os critérios defasagem idade-série e raça/cor. Assim, a razão de vantagens é de 1,17 para o grupo dos alunos com defasagem idade-série comparativamente com o grupo dos alunos que se encontram em idade adequada. De forma idêntica, apurou-se a razão de vantagens do grupo de alunos declarados "Preto" comparativamente com o grupo "Branco" e se verificou que aquela estatística tem o valor de 1,16.

Tabela 2: Resultados do modelo de regressão logística

\begin{tabular}{|c|c|c|}
\hline & B & $\operatorname{Exp}(B)$ \\
\hline Intercepto & $-0,73$ & 0,48 \\
\hline Sexo: Feminino/Masculino & 0,06 & 1,06 \\
\hline Motivação: gosta de Matemática/não gosta & $-0,03$ & 0,97 \\
\hline Defasagem: acima da idade adequada & 0,16 & 1,17 \\
\hline Raça/cor: mulato/branco & $-0,06$ & 0,94 \\
\hline Raça/cor: preto/branco & 0,15 & 1,16 \\
\hline Raça/cor: amarelo/branco & $-0,08$ & 0,92 \\
\hline Raça/cor: indígena/branco & $-0,28$ & 0,76 \\
\hline Nível educacional dos pais: não sei $/ 4^{\mathrm{a}}$ série & $-0,04$ & 0,96 \\
\hline $\begin{array}{l}\text { Nível educacional dos pais: nunca freqüentou a } \\
\text { escola } / 4^{a} \text { série }\end{array}$ & 0,06 & 1,06 \\
\hline Nível educacional dos pais: $8^{\mathrm{a}}$ série $/ 4^{\mathrm{a}}$ série & $-0,03$ & 0,97 \\
\hline Nível educacional dos pais: $11^{\mathrm{a}}$ série $/ 4^{\mathrm{a}}$ série & $-0,02$ & 0,98 \\
\hline Nível educacional dos pais: ensino superior $/ 4^{\mathrm{a}}$ série & $-0,09$ & 0,92 \\
\hline
\end{tabular}

5 Os dados da $4^{\mathrm{a}}$ série representam a população escolar de espectro social mais amplo. 6 Todos os resultados são estatisticamente significativos ao nível de 5\%. 


\section{DISCUSSÃO E OUTROS DESENVOLVIMENTOS}

Ao longo do artigo mostrou-se a importância potencial de fatores psicossociais, nomeadamente a competência percebida nos resultados escolares em Matemática. Foram aplicados os modelos de regressão linear múltipla e de regressão logística aos dados do Saeb-2001, referentes ao Rio de Janeiro, que corroboram aquela relação. Nesses termos, a perspectiva de desenvolvimento escolar deverá contemplar a melhoria da capacidade de auto-avaliação dos alunos, principalmente entre os grupos de risco que foram identificados: 1) alunos com defasagem idade-série, 2) alunos autodeclarados de raça/cor "preta".

Pelo que foi exposto decorre inevitavelmente a relevância de desenvolver no aluno a capacidade de auto-avaliação, de tal modo que lhe permita, num processo de auto-regulação da aprendizagem, ajustar corretamente as suas competências reais às competências esperadas. Caberá também ao professor contemplar esta vertente na sua prática letiva e os procedimentos da avaliação das aprendizagens dos alunos do ensino básico deverão cada vez mais constituir-se como um elemento integrante e regulador da prática educativa, promovendo a qualidade das aprendizagens. Nessa seqüência, Santos (2002) afirma que todo e qualquer ato de regulação tem necessariamente de passar por um papel ativo do aluno. Ora, estando o aluno condicionado ao meio e aos estímulos que deste recebe, percebe-se a importância de num futuro próximo desenvolver estudos semelhantes em diferentes contextos educativos e sociais. Adicionalmente, dever-se-á enquadrar o fator de competência percebida no modelo teórico de eficácia escolar, em particular para investigar a ação do professor na intermediação do processo de auto-avaliação do aluno.

\section{REFERÊNCIAS BIBLIOGRÁFICAS}

BARBOSA, M. E. F.; FERNANDES, C. Modelo multinível: uma aplicação a dados de avaliação educacional. Estudos em Avaliação Educacional, Fundação Carlos Chagas, n. 22, p.135-153, jul./dez. 2000.

A Escola brasileira faz diferença? Uma investigação dos efeitos da escola na proficiência em Matemática dos alunos da $4^{\text {a }}$ série. In: FRANCO, C. (org.). Avaliação, ciclos e promoção na educação. Porto Alegre: ArtMed, 2001. 
BANDURA, A. Conclusion: Reflections on nonability determinants of competence. In: STERNBERG, R.; KOLLIGIAN, J. (eds) Competence considered. New Haven: Yale University, 1990.

Self-efficacy: toward a unifying theory of behavioral change. Psychological Review, n. 84, p. 191-215, 1977.

BONG, M.; CLARK, R. E. Comparison between self-concept and selfefficacy in academic motivation research. Educational Psychologist, v. 34, n. 3, p.139-153, 1999.

BRASIL. Ministério da Educação e Cultura. SAEB 2001: novas perspectivas. Brasília: Inep, 2001.

COKLEY, K. The Impact of college racial composition on African American student's academic self-concept: Academic self-concept as a predictor of academic success among minority and low-socioeconomic status student. Journal of College Student Development, n. 31, p. 402-407, 2002.

DEWEK, C. S. Self-Teories: Their role in motivation, personality, and development. Philadelphia: Psychology Press, 1999.

DIAZ HERNANDEZ, J.; HOFSTRA, V. Correlates of Academic Achievement among Latino Public High School Students. Dissertation Abstracts International, n. 59, p. 1457-1495, 1998.

FARIA, L. Competência percebida: desafios e sugestões para lidar com a excelência. Sobredotação, v. 3, n.2, p. 55-70, 2002.

Concepções pessoais de competência: promover a aprendizagem e o desempenho dos alunos. Inovação, v. 11, n. 2, p. 47-55, 1998.

FERRÃO, M. E.; BELTRÃO, K.; SANTOS, D. O Impacto de políticas de não-repetência sobre o aprendizado dos alunos da $4^{\text {a }}$ série. Pesquisa $e$ Planejamento Econômico, v. 32, n. 3, p. 495-513, dez. 2002.

Políticas de não-repetência e a qualidade da educação: evidências obtidas a partir da modelagem dos dados da $4^{\text {a }}$ série do Saeb-99. Estudos em Avaliação Educacional, n. 26, p.47-73, 2002a. 
FERRÃO, M. E. et al. O Saeb - Sistema Nacional de Avaliação da Educação Básica: objetivos, características e contribuições na investigação da escola eficaz. Revista Brasileira de Estudos de População, v. 18, n. 1/2, p.111-130, 2001.

JUNGE, M. E.; DRETZKE, B. J. Mathematical self-efficacy gender differences in gifted/talented adolescents. Gifted Child Quarterly, n. 39, p. 22-28, 1996.

LANGER, E. J. The Illusion of incompetence. In: PERLMUTTER, L. C.; MONTY, R. A. (eds.). Choice and perceived control. Hillsdale, N. J.: New York, 1979.

LANGER, E. J.; PARK, K. Incompetence: a conceptual reconsideration. In: STERNBERG, R.; KOLLIGIAN, J. (eds). Competence considered. New Haven: Yale University, 1990.

LANGER, E. J.; WEINMAN, M. When Thinking disrups intellectual performance: mindfulness on an overlearned task. Personality and Social Psychology Bulletin, n. 7, p. 240-243, 1981.

LENT, R. W.; BROWN, S. D.; GORE, P. A. Discriminant and predictive validity of academic self-concept, academic self-efficacy, and mathematicsspecific self efficacy. Journal of Counseling Psychology, n. 44, p. 307-315, 1997.

MARSH, H. Verbal and Math Self-concept. An Internal-external frame of reference model. American Educational Research Journal, n. 23, p. 129-149, 1986.

MARSH, H. W.; PARKER, J. W. Determinants of student self-concept: Is it better to be a relatively large fish in a small pond even if you don't learn to swim as well? Journal of Personality and Social Psychology, n. 47, p. 213-231, 1984.

MORGAN, S. L.; METHA, J. D. Beyond the laboratory: Evaluating The Survey Evidence for The Desidentification Explanation of Black-White differences in achievement. Sociology of Education, p.82-101, 2004.

OERTER, R. Structural, ecological, and psychological variables of schooling and their impact on the development of student self-concept. International Journal of Educational Research, n. 23, p. 129-149, 1989. 
PENA, L. Differences in the decision to attend College among African, American, Hispanics, and White. The Journal of Higher Education, v. 71, n. 2, p.130-143, 2000.

PHILLIPS, D. A. The Illusion of incompetence among academically competent children. Child Development, n.55, p. 2000-2016, 1984.

Socialization of perceived academic competence among highly competent children. Child Development, n. 58, p.1308-1320, 1987.

PHILLIPS, D. A.; ZIMMERMAN, M. The development course of perceived competence and incompetence among children. In: STERNBERG, R.; KOLLIGIAN, J. (eds). Competence considered. New Haven: Yale University, 1990.

SAMMONS, P.; HILLMAN, J.; MORTIMORE, P. Key characteristics of effective schools: a review of school effectiveness research. London: University of London, 1995.

SANTOS, Leonor. Auto-avaliação regulada: porquê, o quê e como? In: REORGANIZAÇÃO CURRICULAR DO ENSINO BÁSICO. Avaliação das aprendizagens. Lisboa: Departamento da Educação Básica/Ministério da Educação, 2002.

SIMÕES, M. F. Auto-conceito e desenvolvimento pessoal em contexto escolar. Revista Portuguesa de Pedagogia, XXXI (1,2,3), p. 195-210, 1997.

Editores, 2001.

O Interesse do Auto-Conceito em Educação. Lisboa: Plátano

SOARES, T. M. Influência do professor e do ambiente em sala de aula sobre a proficiência alcançada pelos alunos avaliados no Simave - 2002. Estudos em Avaliação Educacional, Fundação Carlos Chagas, n. 28, p. 103-123, 2003.

SUE, S. Science, ethnicity, and bias: Where have gone wrong? American Psychologist, n. 54, p. 1070-1077, 1999.

Recebido em: maio 2005

Aprovado para publicação em: junho 2005 
